AperTO - Archivio Istituzionale Open Access dell'Università di Torino

\title{
Influence of superpulsed laser therapy on healing processes following tooth extraction
}

\section{This is the author's manuscript}

Original Citation:

\section{Availability:}

This version is available http://hdl.handle.net/2318/132216

since 2019-04-30T09:58:38Z

Published version:

DOI:10.1089/pho.2010.2921

Terms of use:

Open Access

Anyone can freely access the full text of works made available as "Open Access". Works made available under a Creative Commons license can be used according to the terms and conditions of said license. Use of all other works requires consent of the right holder (author or publisher) if not exempted from copyright protection by the applicable law. 


\title{
Influence of Superpulsed Laser Therapy on Healing Processes Following Tooth Extraction
}

\author{
Marco Mozzati, D.D.S., Germana Martinasso, Ph.D., ${ }^{2}$ Nadia Cocero, D.D.S., Renato Pol, D.D.S., \\ Marina Maggiora, Ph.D., ${ }^{2}$ Giuliana Muzio, Ph.D., ${ }^{2}$ and Rosa Angela Canuto, M.D.?
}

\begin{abstract}
Objective: This research studied the effects of laser therapy on healing processes following tooth extraction in healthy human subjects, evaluating some inflammation, osteogenesis, and clinical parameters. Background data: Alveolar healing following tooth extraction is a complex repair process involving different types of tissues, including epithelium and bone. Therefore, it can be advantageous to use techniques able to influence the healing

AU1 of both tissues. Patients and methods: Ten healthy human subjects with indications for bilateral tooth extraction entered the split-mouth study. The subject/patient becomes his/her own control, thereby eliminating all individual differences in response to laser treatment. This consisted of: 904-nm laser, $33 \mathrm{~W}$ peak power, $30 \mathrm{KHz}$, $200 \mathrm{~ns}$, average power $200 \mathrm{~mW}$, illuminated area $1 \mathrm{~cm}^{2}, 200 \mathrm{~mW} / \mathrm{cm}^{2}, 15 \mathrm{~min}, 180 \mathrm{~J}, 180 \mathrm{~J} / \mathrm{cm}^{2}$. In each patient, one post-extraction site was treated with laser radiation, whereas the other was left untreated as a control. Softtissue specimens were removed from the extraction site before tooth extraction (T0) and 7 days after from extraction (T7); expression of inflammatory and osteogenesis parameters was evaluated on these specimens. The clinical parameter "pain" was evaluated for each subject. Results: Superpulsed laser irradiation prevented the increase of interleukin (IL)-1 $\beta$, IL-6, IL-10, and cyclooxygenase-2 (COX-2), and induced an insignificant increase in collagen at 7 days after extraction, versus levels on day of extraction; no changes were found in the other parameters examined. Patients reported less pain at the site treated with superpulsed laser irradiation than at the control site. Conclusions: This study suggests that superpulsed laser irradiation may be a treatment of choice for patients scheduled for tooth extraction, as it provides clinical efficacy, is safe and well tolerated, and is able to prevent inflammation.
\end{abstract}

\section{Introduction}

A LEOLAR HEALING FOLLOWING TOOTH EXTRACTION is a complex repair process involving different types of tissues, including epithelium and bone. In healthy subjects, epithelial cells start to migrate early during the first day postextraction and their proliferation is already marked by day 4 . Bone production begins at 10 days after extraction ${ }^{1}$ and is no longer evident at 20 weeks. ${ }^{2}$

Synthetic bone substitutes can be used to accelerate bone repair in tooth extraction; these include various types of hydroxyapatite and synthetic glasses. ${ }^{3}$ As these substitutes especially target bone repair, other techniques could be tested.

Various studies have addressed the application of laser therapy to general dental practice, ${ }^{4-6}$ such as, in particular, low-level laser therapy (LLLT). No adverse effects have been demonstrated for LLLT, $^{7-9}$ and it is thought to reduce pain, accelerate wound healing, and reduce the inflammatory process. ${ }^{7-9}$ The beneficial effects of LLLT were also demonstrated by in vitro experiments that showed LLLT to enhance bone remodeling, ${ }^{10}$ reduce inflammatory conditions, ${ }^{11}$ and induce human gingival fibroblast proliferation. ${ }^{12}$

There is little available evidence concerning the influence of monochromatic light on either periodontal or peri-implant wound healing, derived from experimental animal studies and randomized controlled clinical trials, ${ }^{13}$ and the benefit over conventional treatment procedures is in doubt. However, a literature review of studies regarding wound healing in general identified 47 relevant studies in rodents. Findings from these consistently demonstrated the ability of laser or monochromatic light therapy to photobiomodulate (typically to stimulate) wound healing processes in experimental wounds in rats and mice, and strongly support the case for

\footnotetext{
${ }^{1}$ Oral Surgery Unit, Dentistry Section, Department of Biomedical Sciences and Human Oncology, School of Dentistry, University of Turin, Turin, Italy.

${ }^{2}$ Department of Experimental Medicine and Oncology, University of Turin, Turin, Italy.
} 
further controlled research in humans. ${ }^{14}$ LLLT slightly reduced the intensity of inflammatory reactions, as well as substantially enhancing the epithelization process, at days 8 and 14. It also appeared to stimulate deposition of collagen fibers in the final stages of wound healing. The LLLT protocol produced some improvements in wound healing by second intention in rodents. ${ }^{15}$ In another study, the effect of the use of laser light was more evident at early stages of healing. ${ }^{16}$

Studies on the healing of bone defects and fractures, and the osseointegration of biomaterial, are numerous, including some using cell cultures and animal models, as well as clinical studies. These have reported a positive effect of LLLT on bone healing. The use of LLLT for biostimulation of alveolar bone repair has therefore been steadily increasing. As a bone attachment stimulating factor, LLLT could be used by dentists in cases in which negative factors are present that are predictive of poor osseointegration. It represents an important improvement in dental practice.

There are different types of lasers to use for photobiostimulation, producing continuous, pulsed, or superpulsed irradiation. Their biostimulation effect has been reported in both in vitro and in vivo studies. ${ }^{710,17-20}$

At present, no studies are available concerning the use of laser therapy to improve healing processes following tooth extraction. The present study examined the effects of laser therapy on healing processes following tooth extraction in healthy human subjects, evaluating some inflammation, osteogenesis, and clinical parameters. We used a laser with superpulsed irradiation, because evident advantages have been reported with this type of laser..$^{10,21,22}$

\section{Patients and Methods}

\section{Subjects}

Ten human healthy subjects, aged 18-35 years (mean 22.5 years), with indications for bilateral molar extraction, entered the study. Selection was based on the absence of any local or systemic disease; informed consent was obtained from all patients entering the study. The study protocol was approved by the Ethics Committee of Turin University. This was a split-mouth study, in which the subject/patient becomes his/her own control, thereby eliminating all individual differences in response to laser treatment.

\section{Surgical protocol}

First, two molar extractions were performed, in the same surgical session. After locoregional anaesthesia (mepivacaine $2 \%$ with adrenaline 1:100000), molar extraction were achieved through luxation and avulsion with a clamp. In each patient, one post-extraction site was treated with laser irradiation, while the other was left untreated as a control.

F1 Left and right sockets were assigned randomly (Figure 1). This provided the best possible control group, because both treatments were given to the same patient, with the same surgical procedure, in identical microbiologic conditions, and by the same surgeon. In all cases, 3-0 silk sutures were used to suture the alveolar mucosa; they were removed after 7 days. Patients were given antibiotic ( $1 \mathrm{~g}$ amoxicillin every $12 \mathrm{~h}$ for 6 days) and oral anti-inflammatory treatment ( $400 \mathrm{mg}$ ibuprofen every $12 \mathrm{~h}$ for 3 days), because similar
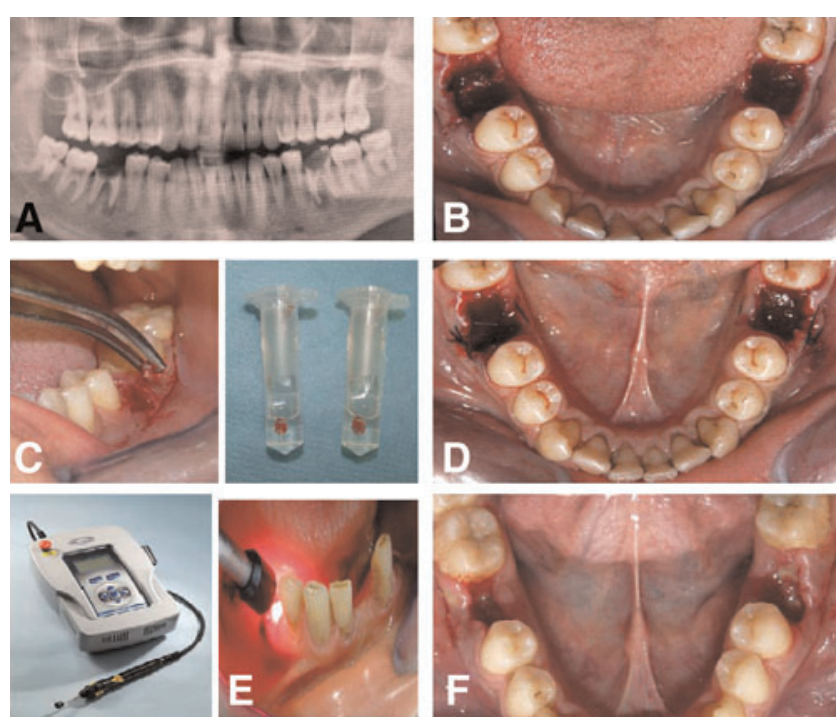

FIG.1. Case report: protocol of extraction and laser treatment. A: All patients were sent for radiological examination, which included a dental panoramic radiograph (OPT). B: Two molar extractions were performed at a single surgical session. C: Soft-tissue specimens were removed from around the tooth prior to extraction and from the post-extraction socket after 7 days. All specimens were placed in RNA Later solution (Qiagen, Milan, Italy) and maintained at $-80^{\circ} \mathrm{C}$ until use. D: 3-0 silk sutures were used to suture the alveolar mucosa. E: After tooth extraction, one post-extraction site was treated with superpulsed laser irradiation on days 3 and 5 post-surgery. A Lumix 2 HFPL Dental device IR (904$910 \mathrm{~nm}$ ) Gallium Arsenide laser (Fisioline s.n.c., Verduno, Cuneo, Italy) was used. F: Sutures were removed after 7 days.

research is in progress on patients with systemic or immunosuppressive diseases. Therefore, as these patients need antibiotic and anti-inflammatory therapy, the drugs were also administered in the present study in order to compare further the sick patients with healthy ones.

Mesial or distal specimens of soft tissue (Figure 1) were surgically incised and removed by scalpel from the extraction site at the following times: before tooth extraction (T0) and after 7 days (T7). The specimens of mucosa were $3 \mathrm{~mm} \times$ $2 \mathrm{~mm}$ in size. All specimens were placed in RNA Later solution (Qiagen, Milan, Italy), and maintained at $-80^{\circ} \mathrm{C}$ until use.

\section{Laser treatment}

In each patient, one post-extraction site was treated with superpulsed laser irradiation, immediately after molar extraction and at days 3 and 5. A Lumix 2 HFPL dental device IR (904-910 nm) gallium arsenide laser (Fisioline s.n.c., Verduno, Cuneo, Italy) was used, with the following experimental parameters: pulse width $200 \mathrm{~ns}$, minimum peak power $33 \mathrm{~W}$, average out power $200 \mathrm{~mW}$ (measured by absolute measurer), illuminated area $1 \mathrm{~cm}^{2}$, irradiance $200 \mathrm{~mW} / \mathrm{cm}^{2}$, frequency $30 \mathrm{kHz}$, exposure time $15 \mathrm{~min}$, total energy $180 \mathrm{~J}$. The dose administered was $180 \mathrm{~J} / \mathrm{cm} 2$. The laser probe was placed in contact with the mucosa after checking bleeding, covering the alveolar socket without moving. The 
patient was not aware of the side that was being treated with the laser, because a non-working laser was used for the untreated site. Specimens of soft tissue were removed as described previously (Figure 1).

\section{Biological factor analysis}

The specimens removed from around the control teeth (not treated with laser irradiation) and from around teeth treated with laser irradiation were processed to determine expression of inflammatory and osteogenesis parameters, using real-time polymerase chain reaction (PCR). The inflammatory cytokines interleukin (IL)- $1 \beta$, IL-6, IL-10, transforming growth factor-beta (TGF- $\beta$ )2, cyclooxygenase-2 (COX-2), bone morphogenetics protein (BMP)-4 and BMP-7, peroxisome proliferator-activated receptor (PPAR)- $\beta$, and collagen type I and type III were examined.

Total RNA was extracted from specimens using the NucleoSpin RNA II Kit (Macherey-Nagel GmbH \& Co. KG, Düren, Germany). Real-time PCR was performed with single-stranded cDNA prepared from total RNA $(1 \mu \mathrm{g})$ using a high-capacity cDNA archive kit (Applied Bio Systems, Foster City, CA).

The forward (FW) and reverse (RV) primers shown in Table 1 were designed using Beacon Designer ${ }^{\circledR}$ software (Bio-Rad, Hercules, CA). Twenty-five microliters of a PCR mixture containing cDNA template equivalent $40 \mathrm{ng}$ of total RNA, 5 pmols each of FW and RV primers, and $2 \times$ IQ SYBR Green SuperMix (Bio-Rad, Hercules, CA) were amplified using an iCycler PCR instrument (Bio-Rad, Hercules, CA) with an initial melt at $95^{\circ} \mathrm{C}$ for $10 \mathrm{~min}$, followed by 35-40 cycles at $95^{\circ} \mathrm{C}$ for $40 \mathrm{sec}$, annealing temperature for each primer set for $40 \mathrm{sec}$, and $72^{\circ} \mathrm{C}$ for $40 \mathrm{sec}$. A final extension of $7 \mathrm{~min}$ at $72^{\circ} \mathrm{C}$ was applied. Each sample was tested in duplicate, and threshold cycle $(\mathrm{Ct})$ values from each reaction were averaged. For both control and laser specimens, the change in expression was defined as that detected in the specimen taken 7 days after tooth extraction (T7) versus that detected in the specimen taken before extraction (T0), calculated as $2^{-\Delta \Delta \mathrm{Ct}}$, where

$$
\begin{aligned}
\Delta \mathrm{Ct} & =\mathrm{Ct}_{\text {sample }}-\mathrm{Ct}_{\mathrm{GAPDH}} \text { and } \Delta \Delta \mathrm{Ct} \\
& =\Delta \mathrm{Ct}_{\mathrm{T} 7 \text { sample }}-\Delta \mathrm{Ct}_{\mathrm{T} 0 \text { sample. }}
\end{aligned}
$$

\section{Clinical evaluation}

For the clinical examination, the patient was asked to score subjective pain on a $10 \mathrm{~cm}$ visual analog scale (VAS), with $0 \mathrm{~cm}$ indicating no pain and $10 \mathrm{~cm}$ indicating the worst possible pain. Pain was evaluated each day at the same time from $2 \mathrm{~h}$ after extraction (T1) to day 7 (T7) post-extraction.

\section{Statistical analysis}

Statistical analyses were performed using the InStat3 software package. All data are expressed as means $\pm \mathrm{SD}$. For each biological factor examined, differences between control and laser site means at T0 and T7 were assessed by analysis of variance, followed by post-hoc Newman-Keuls test.

For pain evaluation, the significance of difference between control and laser site mean values was assessed by the nonparametric Wilcoxon matched pairs signed rank test. Data were taken as being statistically significant for $p<0.05$.

TABLE 1

\begin{tabular}{|c|c|c|c|}
\hline $\begin{array}{c}\text { Gene } \\
\text { Accension number }\end{array}$ & $\begin{array}{c}\text { Sequence } \\
\text { FW (Forward) } \\
R V \text { (Reverse) }\end{array}$ & $\begin{array}{c}\text { T } \\
\text { annealing } \\
\text { No. Cycle }\end{array}$ & Product length \\
\hline GAPDH & FW 5'- GTC GGA GTC AAC GGA TTT GG-3' & $52^{\circ} \mathrm{C}$ & $142 \mathrm{pb}$ \\
\hline NM_002046 & RV 5'- GGG TGG AAT CAT ATT GGA ACA TG-3' & $35 \times$ & \\
\hline IL-1 $\beta$ & FW 5'- GCA CCT TCT TTC CCT TCA TCT TT-3' & $52^{\circ} \mathrm{C}$ & $105 \mathrm{pb}$ \\
\hline AF043335 & RV 5'- GCG TGC AGT TCA GTG ATC GTA-3' & $40 \times$ & \\
\hline COX-2 & FW 5'- TGG TCT GGT CCC TGG TC-3' & $58^{\circ} \mathrm{C}$ & $132 \mathrm{pb}$ \\
\hline NM_00963 & RV 5'- AGT ATT AGC CTG CTT GTC TGG-3' & $30 x$ & \\
\hline IL-6 & FW 5'- CCA GTA CCC CCA GGA GAA GAT T-3' & $52^{\circ} \mathrm{C}$ & $78 \mathrm{pb}$ \\
\hline M14584 & RV 5'- GTC AAT TCG TTC TGA AGA GGT GAG T-3' & $40 \times$ & \\
\hline IL-10 & FW 5'-CCG AGA TGC CTT CAG CAG AG-3' & $60^{\circ} \mathrm{C}$ & $154 \mathrm{pb}$ \\
\hline AY029171 & RV 5'-CAT CAC CTC CTC CAG GTA AAA CT-3' & $30 x$ & \\
\hline TGF- $\beta 2$ & FW 5'- GAG TAC TAC GCC AAG GAG GTT TAC A-3' & $52^{\circ} \mathrm{C}$ & $104 \mathrm{pb}$ \\
\hline NM_003238 & RV 5'- CGA ACA ATT CTG AAG TAG GGT CTG T-3' & $40 \times$ & \\
\hline BMP-4 & FW 5'- CTC GCT CTA TGT GGA CTT C-3' & $58^{\circ} \mathrm{C}$ & $130 \mathrm{pb}$ \\
\hline D30751 & RV 5'- ATG GTT GGT TGA GTT GAG G-3' & $40 \times$ & \\
\hline BMP-7 & FW 5'- GTG GAA CAT GAC AAG GAA T-3' & $58^{\circ} \mathrm{C}$ & $65 \mathrm{pb}$ \\
\hline NM_001719 & RV 5'- GAA AGA TCA AAC CGG AAC-3' & $40 \times$ & \\
\hline PPAR- $\beta$ & FW 5'- AAA GAA GGC CCG CAG CAT-3' & $56^{\circ} \mathrm{C}$ & $170 \mathrm{pb}$ \\
\hline XM_165760 & RV 5'- CTG GAT GTC GTG GAT CAC AAA-3' & $40 \times$ & \\
\hline Collagen type I & FW 5'- GAG GAA ACT GTA AGA AAG G-3' & $58^{\circ} \mathrm{C}$ & $150 \mathrm{pb}$ \\
\hline NM_000089 & RV 5'- GTT CCC ACC GAG ACC-3' & $35 \times$ & \\
\hline Collagen type III & FW 5'- ACT CGC CCT CCT AAT GG- 3' & $59^{\circ} \mathrm{C}$ & $148 \mathrm{pb}$ \\
\hline NM_000090 & RV 5'- GGC ATG ATT CAC AGA TTC C- 3' & $35 \times$ & \\
\hline
\end{tabular}

Forward and reverse primers. 

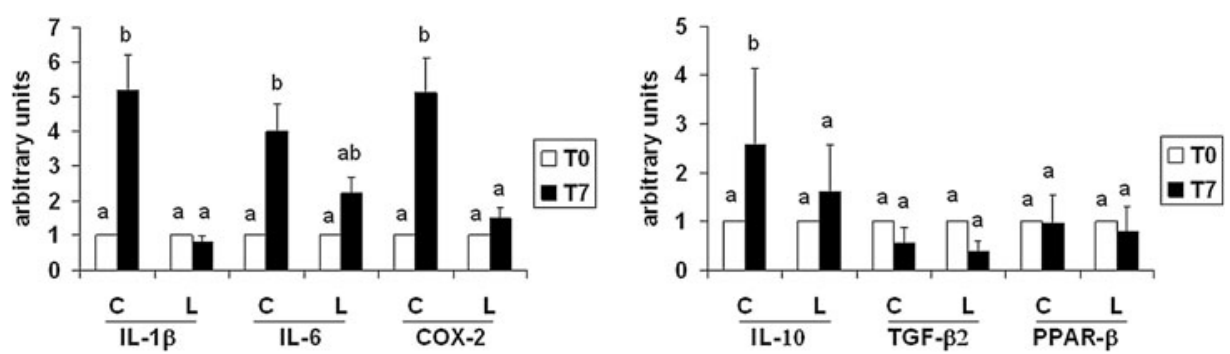

FIG. 2. Expression of IL- $1 \beta$, IL6 , COX-2, IL-10, TGF- $\beta 2$, and PPAR- $\beta$ in soft-tissue specimens removed from around the untreated tooth (control) and that treated with superpulsed laser irradiation at T7. Control site (C) and superpulsed laser irradiated site (L) values at T7 are referred to their respective T0 values, taken as 1 (white bar). The values are means \pm S.D. of 10 subjects. For each biological factor, means with different letters are significantly different from one another $(p<0.05)$ as determined by analysis of variance followed by post-hoc Newman-Keuls analysis.

\section{Results}

\section{Biological factor analysis}

Analysis of the biological factors involved in the inflammation process and in healing after molar extraction is

F2 shown in Figures 2 and 3. Soft-tissue specimens were reF3 moved before extraction (T0) and from the socket 7 days after extraction (T7). One post-extraction site was treated with laser (L) while the other was treated with a nonworking laser as a control site (C). Left and right sockets were assigned randomly. Figure 2 shows the inflammatory factors, namely IL-1 $\beta$, IL-6, and COX-2. In control specimens, all three factors increased significantly at $\mathrm{T} 7$ versus the corresponding value at $\mathrm{T} 0$, which was taken as 1 . For sites treated with superpulsed laser irradiation, on the other hand, no significant increase was observed at T7 versus T0. Therefore, levels of IL- $1 \beta$ and COX-2 were significantly lower at laser sites versus control sites, except in the case of IL-6.

Figure 2 also shows the biological factors involved in the healing process: IL-10, TGF- $\beta 2$, and PPAR- $\beta$. The latter two factors showed no variation, whereas Il-10 unexpectedly decreased at T7 in soft-tissue specimens taken from sites treated with superpulsed laser irradiation, which did not occur with controls. Figure 3 illustrates the biological factors, BMP4, and BMP7, that are involved in bone healing. No variation was found in levels of these factors, probably because 7 days is too short a time to see evidence of bone healing. As regards collagen I and III, again no significant modification was evident, although there was a trend toward an increase at laser-treated sites but not at controls (Figure 3).

\section{Clinical evaluation}

For the clinical examination, the patient was asked to score his/her feeling of pain on a $10 \mathrm{~cm}$ visual analogue scale (VAS), with $0 \mathrm{~cm}$ reflecting no pain and $10 \mathrm{~cm}$ reflecting the worst pain possible. The pain was evaluated each day at the same time from $2 \mathrm{~h}$ after extraction (T1) to day 7 (T7) in the postoperative period. Figure 4 shows that patients reported less pain at the site treated with superpulsed laser irradiation than they did at the control site.

\section{Discussion}

This research comprises the first split-mouth study of the effect of laser irradiation on molar-extraction site healing. The subject/patient becomes his/her own control, which eliminates all individual differences in response to laser treatment. It is also the first study examining the healing processes following molar extraction in healthy subjects, evaluating biological factors rather than simply clinical aspects.

Laser treatment is an innovative approach, although it is increasingly used in medicine. It has been shown to produce several different effects, including pain relief, wound healing, and nerve regeneration. It has potential antimicrobial and biostimulating effects when applied to oral tissues, for example improving wound healing, enhancing epithelization after periodontal surgery, minimizing edema after thirdmolar surgery, and preventing oral mucositis. ${ }^{23-28}$

It has been demonstrated that laser therapy stimulates cell proliferation and the formation of lymphatic and blood vessels, ${ }^{29,30}$ and it may improve bone mineralization. ${ }^{10,31,32}$ The effect of laser therapy on bone regeneration has been the
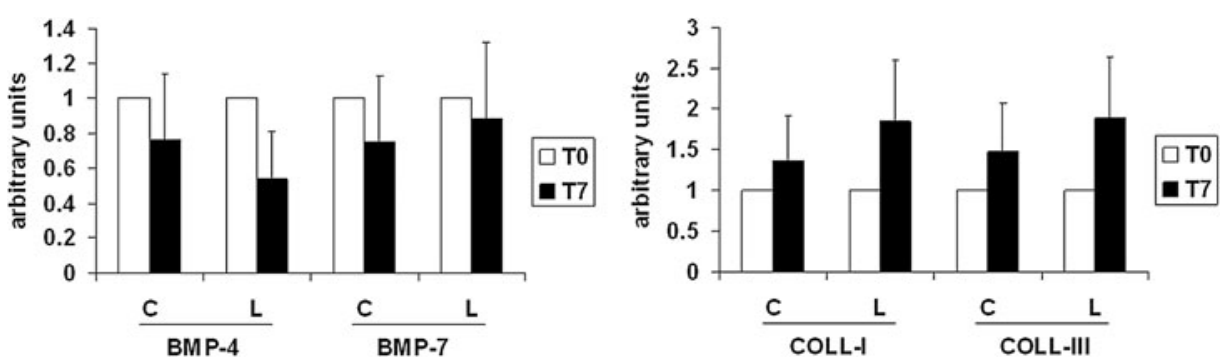

FIG. 3. Expression of BMP-4, BMP-7, collagen I (COLL-I), and collagen III (COLL-III) in softtissue specimens removed from around the untreated tooth (control) and that treated with superpulsed laser irradiation at T7. Control (C) and superpulsed laser irradiation $(\mathrm{L})$ values at $\mathrm{T} 7$ are referred to their respective T0 values, taken as 1 (white bar).

The values are means \pm S.D. of 10 subjects. For each biological factor, means with different letters are significantly different from one another $(p<0.05)$ as determined by analysis of variance followed by post-hoc Newman-Keuls analysis. 


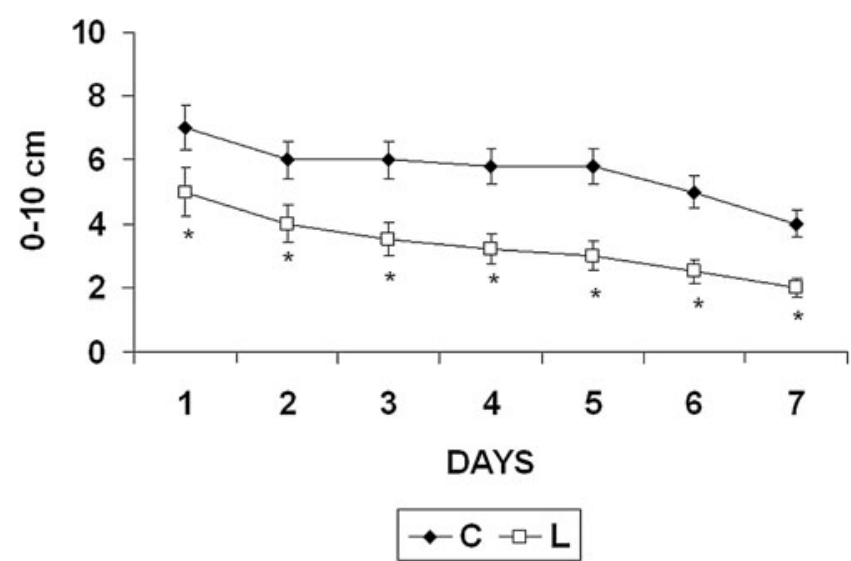

FIG. 4. Visual analogue scale (VAS) for pain measurement at untreated site (C) and at that treated with superpulsed laser irradiation (L). Values are means \pm S.D. of 10 patients. The significance of differences between $C$ and $L$ means was assessed by non-parametric Wilcoxon test ( $p<0.05 \mathrm{~L}$ versus $\mathrm{C}$ ).

focus of recent research, including in dentistry. Studies have investigated the ability of this irradiation to stimulate both bone production and bone-implant interaction. ${ }^{10,33}$

As for biological factors, the superpulsed laser irradiation used in this study acted on pro-inflammatory cytokines, preventing an increase of the level of IL- $1 \beta$ and IL- 6 at 7 days after the molar extraction versus their level immediately prior to extraction, whereas these two cytokines increased at control sites. Moreover, laser irradiation also prevented an increase of COX-2 at 7 days after tooth extraction over the level detected prior to extraction. COX-2 is an enzyme involved in the metabolism of arachidonic acid, producing prostaglandin E2 (PGE2), a substance playing an important role during the inflammatory process. COX-2 increased at control sites, as did IL-1 $\beta$ and IL-6.

Unexpectedly, the IL-10 level decreased at sites treated with laser at 7 days after tooth extraction below the preextraction level; however, this decrease did not produce an increase in the inflammatory process, as during the same interval the pro-inflammatory cytokines had decreased. This result is in contrast with reports in the literature. IL-10 is a pleiotropic cytokine that regulates a variety of functions of hemopoietic cells. Its principal day-to-day function appears to be that of containing and eventually terminating inflammatory responses. Thus IL-10 facilitates the elimination of infectious organisms while causing minimal damage to host tissues. Early clinical trials suggest that IL-10 is safe and may be of use in treating autoimmune and inflammatory conditions; it strongly inhibits the production of IL- $1 \alpha$, IL- $1 \beta$, IL- 6 , IL-10 itself, IL-12, IL-18, granulocyte-macrophage colonystimulating factor (GM-CSF), granulocyte colony-stimulating

AU3 factor (G-CSF), M-CSF , tumor necrosis factor (TNF), leuke-

AU4 mia inhibitory factor (LIF), and PAF by activated monocytes/macrophages. The inhibitory effects of IL-10 on IL-1 and TNF production are crucial to its anti-inflammatory activities, because these cytokines often have synergistic activities on inflammatory pathways and processes, and amplify these responses by inducing secondary mediators, such as chemokines, prostaglandins, and PAF. IL-10 has been found to inhibit the production of PGE2 by downregulating COX-2 expression. ${ }^{34}$

As for the other parameters evaluated, i.e. TGF- $\beta 2$, PPAR$\beta$, and factors involved in osteogenesis, their levels were found to be unchanged up to day 7 . For the osteogenesis parameters, the observation time was probably too short, therefore specimens of the mucosa around the healing socket would need to be taken on subsequent days.

The clinical parameter of pain was reported by patients to be less at the site treated with laser therapy than at the other control site. This effect is in partial agreement with results of another study: a group of patients treated with therapeutic laser exhibited lower intensity of postoperative pain, swelling, and trismus than did the control group, but the difference was not reported to be statistically significant. $^{35}$

Our findings might have a significant clinical impact, as laser treatment is simple to perform, does not increase morbidity, and has no side effects. Moreover, the results of this study may stimulate the use of laser treatment for patients with systemic diseases. In fact, preliminary results obtained on patients waiting for liver transplantation, who had undergone tooth bilateral extraction, showed that laser treatment reduced postoperative pain at the laser-treated site in comparison with the control site (data not shown). Therefore, this laser technique can produce significant benefits in compromised patients. Moreover, it is to note that this technique is not invasive and does not produce adverse side effects.

\section{Conclusions}

This study suggests that superpulsed laser irradiation currently appears to be a treatment of choice, providing clinical efficacy and being safe and well tolerated, especially for patients who need conservative treatment.

\section{Summary}

Soft-tissue specimens were removed from around the tooth before extraction (T0) and from the socket 7 days after extraction (T7). One post-extraction site was treated with laser while the other was left untreated as a control site.

In control specimens, the inflammatory factors, IL- $1 \beta$, IL-6, and COX-2, increased significantly at T7 compared to the corresponding value at $\mathrm{T} 0$, whereas for sites treated with superpulsed laser irradiation, no significant increase was observed at $\mathrm{T} 7$ versus $\mathrm{T} 0$. There was a trend toward an increase of collagen I and III at laser-treated sites compared to controls .

As a clinical parameter, patients reported less pain at the site treated with superpulsed laser irradiation than at the control site.

\section{Acknowledgments}

This work was supported by grants from the Piedmont Regional Government and from Turin University, Italy.

\section{Author Disclosure Statement}

No competing financial interests exist. 


\section{References}

1. Boyne, P.J. (1966). Osseous repair of the postextraction alveolus in man. Oral Surg. Oral Med. Oral Pathol. 21, 805813.

2. Ahn, J.J., and Shin, H.I. (2008). Bone tissue formation in extraction sockets from sites with advanced periodontal disease: a histomorphometric study in humans. Int. J. Oral Maxillofac. Implants 23, 1133-1138.

3. Chiapasco, M., Casentini, P., and Zaniboni, M. (2009). Bone augmentation procedures in implant dentistry. Int. J. Oral Maxillofac. Implants 24, 237-259.

4. Walsh, L.J. (2003). The current status of laser applications in dentistry. Aust. Dent. J. 48, 146-155.

5. Chukwuneke, F., and Onyejiaka, N. (2007). Management of postoperative morbidity after third molar surgery: a review of the literature. Niger. J. Med. 16, 107-112.

6. Aoki, A., Sasaki, K.M., Watanabe, H., and Ishikawa, I. (2004). Lasers in nonsurgical periodontal therapy. Periodontol. 2000 36, 59-97.

7. Obradović, R.R., Kesić, L.G., and Pesevska, S. (2009). Influence of low-level laser therapy on biomaterial osseointegration: a mini-review. Lasers Med. Sci. 24, 447-451.

8. Qadri, T., Miranda, L., Tunér, J., and Gustafsson, A. (2005). The short-term effects of low-level lasers as adjunct therapy in the treatment of periodontal inflammation. J. Clin. Periodontol. 32, 714-719.

9. Sun, G., and Tunér, J. (2004). Low-level laser therapy in dentistry. Dent. Clin. North Am. 48, 1061-1076.

10. Saracino, S., Mozzati, M., Martinasso, G., Pol, R., Canuto, R.A., and Muzio, G. (2009). Superpulsed laser irradiation increases osteoblast activity via modulation of bone morphogenetic factors. Lasers Surg. Med. 41, 298-304.

11. Nomura, K., Yamaguchi, M., and Abiko Y. (2001). Inhibition of interleukin-1beta production and gene expression in human gingival fibroblasts by low-energy laser irradiation. Lasers Med. Sci. 16, 218-223.

12. Almeida-Lopes, L., Rigau, J., Zângaro, R.A., Guidugli-Neto, J., and Jaeger, M.M. (2001). Comparison of the low level laser therapy effects on cultured human gingival fibroblasts proliferation using different irradiance and same fluence. Lasers Surg. Med. 29, 179-184.

13. Schwarz, F., Aoki, A., Sculean, A., and Becker, J. (2009). The impact of laser application on periodontal and peri-implant wound healing. Periodontol. 2000 51, 79-108.

14. Peplow, P.V., Chung, T.Y., and Baxter, G.D. (2009). Laser photobiomodulation of wound healing: a review of experimental studies in mouse and rat animal models. Photomed. Laser Surg. 28, 291-325.

15. Gonzaga Ribeiro, M.A., Cavalcanti de Albuquerque, R.L., Santos Barreto, A.L., Moreno de Oliveira, V.G., Santos, T.B., and Freitas Dantas, C.D. (2009). Morphological analysis of second-intention wound healing in rats submitted to $16 \mathrm{~J} /$ cm 2 lambda 660-nm laser irradiation. Indian J. Dent. Res. 20, 390-396.

16. Medeiros, J.L., Nicolau, R.A., Nicola, E.M., Dos Santos, J.N., and Pinheiro, A.L. (2009). Healing of surgical wounds made with lambda970-nm diode laser associated or not with laser phototherapy (lambda655 nm) or polarized light (lambda400-2000 nm). Photomed. Laser Surg. Oct 26. [Epub ahead of print]

17. Saltmarche, A.E. (2008). Low level laser therapy for healing acute and chronic wounds-The extendicare experience. Int. Wound J. 5, 351-360.
18. Ivandic, B.T., and Ivandic, T. (2008). Low-level laser therapy improves vision in patients with age-related macular degeneration. Photomed. Laser Surg. 26, 241-245.

19. Reis, S.R., Medrado, A.P., Marchionni, A.M., Figueira, C., Fracassi, L.D., and Knop, L.A. (2008). Effect of $670-\mathrm{nm}$ laser therapy and dexamethasone on tissue repair: a histological and ultrastructural study. Photomed. Laser Surg. 26, 307-313.

20. De Oliveira, R.F., Oliveira, D.A., Monteiro, W., Zangaro, R.A., Magini, M., and Soares, C.P. (2008). Comparison between the effect of low level laser therapy and low-intensity pulsed ultraultrasonic irradiation in vitro. Photomed. Laser Surg. 26, 6-9.

21. Cafaro, A., Albanese, G., Arduino, P.G., Mario, C., Massolini, G., Mozzati, M., and Broccoletti, R. (2010) Effect of lowlevel laser irradiation on unresponsive oral lichen planus: early preliminary results in 13 patients. Photomed. Laser Surg. Aug 25. [Epub ahead of print].

22. Scoletta, M., Arduino, P.G., Reggio, L., Dalmasso, P., and Mozzati, M. (2010). Effect of low-level laser irradiation on bisphosphonate-induced osteonecrosis of the jaws: preliminary results of a prospective study. Photomed. Laser Surg. $28,179-84$.

23. Gál, P., Mokrý, M., Vidinský, et al. (2009). Effect of equal daily doses achieved by different power densities of lowlevel laser therapy at $635 \mathrm{~nm}$ on open skin wound healing in normal and corticosteroid-treated rats. Lasers Med. Sci. 24, 539-547.

24. Gál, P., Vidinský, B., Toporcer, T., et al. (2006). Histological assessment of the effect of laser irradiation on skin wound healing in rats. Photomed. Laser Surg. 24, 480-448.

25. Ozcelik, O., Cenk Haytac, M., Kunin, A., and Seydaoglu, G. (2008). Improved wound healing by low-level laser irradiation after gingivectomy operations: a controlled clinical pilot study. J. Clin. Periodontol. 35, 250-254.

26. Amorim, J.C., de Sousa, G.R., de Barros Silveira, L., Prates, R.A., Pinotti, M., and Ribeiro, M.S. (2006). Clinical study of the gingiva healing after gingivectomy and low-level laser therapy. Photomed. Laser Surg. 24, 588-594.

27. Markovic, A., and Todorovic, L.J. (2007). Effectiveness of dexamethasone and low-power laser in minimizing oedema after third molar surgery: a clinical trial. Int. J. Oral Maxillofac. Surg. 36, 226-229.

28. Antunes, H.S., de Azevedo, A.M., da Silva Bouzas, L.F., et al. (2007). Lowpower laser in the prevention of induced oral mucositis in bone marrow transplantation patients: a randomized trial. Blood 109, 2250-2255.

29. Pourzarandian, A., Watanabe, H., Aoki, A., et al. (2004). Histological and TEM examination of early stages of bone healing after Er:YAG laser irradiation. Photomed. Laser Surg. 22, 342-350.

30. Polosukhin, V.V. (2000). Ultrastructure of the blood and lymphatic capillaries of the respiratory tissue during inflammation and endobronchial laser therapy. Ultrastruct. Pathol. 24, 183-189.

31. Pires Oliveira, D.A., de Oliveira, R.F., Zangaro, R.A., and Soares, C.P. (2008). Evaluation of low-level laser therapy of osteoblastic cells. Photomed. Laser Surg. 26, 401-404.

32. Pinheiro, A.L., and Gerbi, M.E. (2006). Photoengineering of bone repair processes. Photomed. Laser Surg. 24, 169178.

33. Maluf, A.P., Maluf, R.P., da Rocha Brito, C., França, F.M., and de Brito, R.B., Jr. (2010). Mechanical evaluation of the influence of low-level laser therapy in secondary stability of 


\section{LASER THERAPY AND TOOTH EXTRACTION}

implants in mice shinbones. Lasers Med. Sci. Apr 15. [Epub ahead of print]

34. Moore, K.W., de Waal Malefyt, R., Coffman, R.L., and O'Garra, A. (2001). Interleukin-10 and the interleukin-10 receptor. Annu. Rev. Immunol. 19, 683-765.

35. Amarillas-Escobar, E.D., Toranzo-Fernández, J.M., Martínez-Rider, R., et al. (2010). Use of therapeutic laser after surgical removal of impacted lower third molars. J. Oral Maxillofac. Surg. 68, 319-324.
Address correspondence to: Rosa Angela Canuto Dipartimento di Medicina ed Oncologia Sperimentale Università di Torino Corso Raffaello 30, 10125 Torino Italy

E-mail: rosangela.canuto@unito.it 
PHO-2010-2921-ver9-Mozzati_1P.3D 01/18/11 4:53pm Page 8 


\section{AUTHOR QUERY FOR PHO-2010-2921-VER9-MOZZATI_1P}

AU1: You say "both" tissues here but the previous text implies there are more than two types involved. Should "both" be changed to "all"?

AU2: Rewritten as meant?

AU3: Please spell out. Could mean several different things.

AU4: Please spell out.

AU5: Rewritten as meant?

AU6: Please check journal abbreviation. Not in PubMed.

AU7: Please provide title for table.

AU8: Please indicate what " $\mathrm{pb}$ " stands for. 